Derleme

\title{
Entegre Raporlamanın Sürdürülebilir Kalkınma ve İşletmeler Üzerindeki Etkisine İliş̧kin Kavramsal Çerçeve
}

\author{
Cihan ALPTEKIN \\ Sorumlu Yazar, Muş Alparslan Üniversitesi, Sosyal Bilimler MYO, \\ Muhasebe ve Vergi Bölümü \\ c.alptekin@alparslan.edu.tr,_ORCID:0000-0001-7699-4628 \\ İsmail CAN \\ Kırıkkale Üniversitesi, İ̈BF, İşletme Bölümü \\ ican67@gmail.com,ORCID:0000-0002-9404-8034
}

\begin{abstract}
$\ddot{\mathbf{O z}}$
Endüstri devriminden 1970'li yıllara kadar yaşanan süreçte ülkeler kalkınma olgusunu ekonomik büyümeyle özdeşleştirdikleri için sanayileşmeye öncelik verilmiş, işletmelerin sosyal ve doğal çevre üzerindeki olumsuz etkileri görmezden gelinmiştir. Aynı dönemde işletme paydaşlarının bilgi talepleri de finansal bilgiden ibaret olmuştur. Ancak meydana gelen çevresel ve finansal olumsuzluklar ile küreselleşme olgusu hem kalkınma kavramında hem de kurumsal raporlamada önemli değişimleri beraberinde getirmiştir. Böylece ülkelerin gündeminde sürdürülebilir kalkınma olgusu yer almaya başlarken; işletmeler de finansal bilgilerin yanında sürdürülebilirlik bilgilerini raporlamaya başlamıştır. Bu kapsamda çalışmanın amacı mevcut literatür incelenerek, kurumsal raporlamanın ulaştığı son aşama olan entegre raporlamanın işletmeler ve paydaşları için sağladığı faydaların yanı sıra sürdürülebilir kalkınma ile işletmelerin sürdürülebilirliği üzerindeki etkisine dair kavramsal bir çerçeve ortaya koymaktır.
\end{abstract}

Anahtar Kelimeler: Sürdürülebilirlik, Kalkınma, Entegre Raporlama.

JEL Sınıflandırma Kodları: O11, O12, M41

Conceptual Framework for the Impact of Integrated Reporting on Sustainable Development and Businesses ${ }^{1}$

\begin{abstract}
In the process from the industrial revolution to the 1970s, industrialization was prioritized because countries associated the development phenomenon with economic growth, and the negative effects of businesses on the social and natural environment were ignored. In the same period, information requests of business stakeholders consisted of financial information. However, environmental and financial negativities and the phenomenon of globalization have brought along important changes both in the concept of development and in corporate reporting. Thus, while the concept of sustainable development started to take place on the agenda of the countries; businesses have started to report sustainability information as well as financial information. In this context, the aim of the study is to examine the existing literature and to present a conceptual framework regarding the benefits of integrated reporting, which is the last stage of corporate reporting, for businesses and their stakeholders, as well as its impact on sustainable development and the sustainability of businesses.
\end{abstract}

Keywords: Sustainability, Development, Integrated Reporting.

JEL Classification Codes: O11, O12, M41

\footnotetext{
${ }^{1}$ Extended abstract is presented at the end of the article.
}

Geliş Tarihi (Received): 09.10.2021 - Kabul Edilme Tarihi (Accepted): 10.12.2021

Atıfta bulunmak için / Cite this paper:

Alptekin, C. ve Can, İ. (2021). Entegre raporlamanın sürdürülebilir kalkınma ve işletmeler üzerindeki etkisine ilişkin kavramsal çerçeve. Çankırı Karatekin Üniversitesi İ̈BF Dergisi, 11 (2), 781-803. Doi: 10.18074/ckuiibfd.1007561. 


\section{Giriş}

İnsanlık var olduğu günden itibaren kıtlık problemi ile karşı karşıya kalmıştır. Bu sorunu aşabilmek için doğadaki kaynakları kullanan insanoğlu, yerleşik hayata geçmeden önce avcılık ve toplayıcılık yapmış, yerleşik hayata geçtikten sonra ise tarımsal faaliyetlerde bulunmuştur. Söz konusu dönemlerde kendisini de doğanın bir parçası olarak gören insanoğlu, doğadan tabii yollarla elde ettikleriyle yetinmiş ve doğa üzerindeki tahribatı da sınırlı düzeyde kalmıştır. Ancak 18. yüzyılda yaşanan Endüstri Devrimi, üretim miktarını artırdığı gibi buna bağlı olarak kaynak kullanım miktarını da artırmıştır (Karabıçak ve Armağan, 2004, s. 204). Daha önceleri sınırsız kabul edilen doğal kaynakların, Sanayi Devrimi'yle birlikte ulaşılan yüksek üretim ve tüketim süreci neticesinde, tükenmeye başladıkları görülmüş ve bu yeni sürecin doğal dengeyi tahrip ettiği fark edilmeye başlanmıştır (Ergün ve Çobanoğlu, 2012, s. 98).

Küresel çapta yaşanan çevresel kirlilik, ozon tabakasının incelmesi ve canlı türlerinin yok olmaya başlaması gibi sorunlar, ekonomi ile çevrenin karşılıklı bir etkileşim içerisinde yer aldığını ve dolayısıyla bunların beraber gözetilmesi gerektiğini ortaya koymuştur. Nitekim ekonomi ile doğanın karşılıklı bağımlılığının, ülkelerin kalkınma planlarında göz önünde bulundurulması gerektiğiyle ilgili olarak geniş çaplı ilk uyarı Roma Kulübü tarafından 1972 yılında yayımlanan "Büyümenin Sınırları" isimli raporla yapılmıştır. Yine 1972 yılında Birleşmiş Milletler Çevre Konferansı'nda doğal çevre ile kalkınma arasındaki ilişkiye dikkat çekmek için "ekokalkınma" politikası kapsamında sürdürülebilir kalkınmanın ana unsurları olan "insan merkezlilik" ile "gelecek kuşakların kaynaklarının korunması" konuları ön plana çıkarılmıştır (Dulupçu, 2001'den akt. Toprak, 2006, s. 148). Birleşmiş Milletler tarafından 1992 yılında Brezilya'nın Rio de Janeiro kentinde düzenlenen ve 178 ülkenin katılım gösterdiği Çevre ve Kalkınma Konferansı da sürdürülebilir kalkınma kavramının kapsamını geniş̧leten bir organizasyon olmuştur. Bu konferansta kabul edilen Gündem 21 isimli belge ile sürdürülebilir kalkınmanın yanı sıra sürdürülebilir kentleşme, sürdürülebilir tarım ve kırsal gelişim, sürdürülebilir dă̆ ve orman gelişimi ile yönetim gibi birçok alan üzerinde detaylı bir şekilde durulmuştur (Bozlağan, 2010, s. 1020).

Rio de Janeiro'da düzenlenen Çevre ve Kalkınma Konferansı, sürdürülebilir kalkınma konusunun uluslararası gündemde ağırlıklı olarak yer alması bakımından yeni bir dönemin başlangıcını oluşturmuştur. Bununla birlikte 2000 yılında gerçekleştirilen Birleşmiş Milletler Binyıl Zirvesi ise yoksullukla mücadele, ekolojik sürdürülebilirlik, eğitimde firsat eşitliği ve cinsiyet ayrımcılığına karşı 15 yıllık bir süreçte yapılması gerekenlerin hedef olarak belirlendiği uluslararası bir organizasyon olmuştur (Doğru, 2017, s. 34).

Sürdürülebilirlik konusunda ülkeler nezdinde bu gelişmeler yaşanırken, işletmeler açısından da benzer bir süreç söz konusu olmuştur. Nitekim ekonomik olarak 
işletmelerde temel amacın kâr maksimizasyonu olduğu 1970'li yıllara kadar kurumsal raporlama yalnızca finansal raporlamadan ibaret olmuştur (Önder, 2018, s. 32). İşletme faaliyetlerinin toplum ve çevre üzerindeki etkilerinin daha fazla tartışılmaya başlandığı 1980'li yıllardan itibaren, finansal raporlamanın tek başına işletmelerin gerçek durumunu yansıtamadığı görüşü önem kazanmıştır. Bu yüzden kurumsal raporlamada, finansal raporların yanında işletme yönetiminin açıklamaları, yönetişim ve ücretlendirmeye dair bilgiler ve çevresel raporlar da yayımlanmaya başlamıştır (Aydın, 2015, s. 21). 2000'li yıllarda çevresel raporlama; sosyal, çevresel, yönetişim ve ekonomik faktörleri kapsayacak şekilde genişleyerek, sürdürebilirlik raporlamasına dönüşmüştür (Sevim ve Bayhan, 2018, s. 11). Ancak işletmeler tarafından, birbirlerinden bağımsız olarak yayımlanan finansal ve sürdürülebilirlik raporlarının aşırı detaylı olmaları ve aralarındaki kopukluk, işletme paydaşlarının bu raporları anlamalarını ve dolayısıyla işletmelerin uzun vadede nasıl değer yarattıklarını anlamalarını zorlaştırmıştır (Aras ve Sarığlu, 2015, s. 37). Ayrı ayrı hazırlanıp bilgi kullanıcılarının kullanımına sunulan raporların işletmelerin gerçek değerleri, performansları ve gelecekleriyle ilgili kapsamlı bir bakış açısına sahip olmamaları, farklı bir raporlama ihtiyacını ortaya çıkarmıştır (Kaya, 2015, s.114).

Geleneksel raporlamanın eksikliklerini gidermek amacıyla ortaya çıkan kurumsal raporlama şekli entegre raporlama olarak ifade edilmektedir. Biçimsel olarak, finansal raporlamayla sürdürülebilirlik raporlamasının tek dokümanda birleştirilmesi olarak tarif edilebilen entegre raporlama, işletmelerin nasıl değer yarattıklarını, sürdürülebilirlik verilerinin finansal verileriyle olan ilişkilerini, iş modellerini, stratejilerini, geleceğe dair beklentilerini, risk ve fursatlarını, güçlü ve zayıf taraflarını, paydaşlarıyla olan ilişkilerini, kullandıkları sermaye öğelerini, faaliyetlerinin çevre ve toplum üzerindeki etkilerini şeffaf, öz ve etkili bir şekilde paylaşabilecekleri bir kurumsal raporlama şeklidir.

Bu çalışma kapsamında temel olarak entegre raporlamanın, ekonominin en önemli yapı taşları olan işletmelerin sürdürülebilirliği ve sürdürülebilir kalkınma üzerindeki etkisi analiz edilmeye çalışılmıştır. $\mathrm{Bu}$ bakımdan öncelikle sürdürülebilirlik, sürdürülebilir kalkınma ve entegre raporlama kavramları hakkında gerekli bilgiler verilmiş, daha sonra entegre raporlama uygulamasının işletmelerin sürdürülebilirliğine katkısı ve bu işletmelerin de sürdürülebilir kalkınma üzerindeki etkisi değerlendirilmiştir.

\section{Sürdürülebilirlik ve Sürdürülebilir Kalkınma Kavramları}

Sürdürülebilirlik kavramı, kökeni bakımından Latince "sustinere" kelimesinden türetilen ve İngilizce bir kavram olan "sustainability” kelimesinin Türkçe karşılığ1 olup; sözlüklerde sürdürmek, devam ettirmek, var olmak ve sağlamak şeklinde karş1lık bulmaktadır (Onions, 1964, 2095'ten akt. Tıraş, 2012, s. 59). Kavram olarak sürdürülebilirlik, herhangi bir şeyin devam etmesi ya da devam ettirilmesi anlamına gelirken, içinde bulunulan zaman dilimine ve gelecek zamana birlikte 
atıf yapmaktadır. $\mathrm{Bu}$ kapsamda ekonomi ile ilişkilendirildiği vakit sürdürülebilirlik, nihai amacı kâr sağlamak olan geleneksel kalkınma modellerinin tersine, mevcut dünya kaynaklarının korunmasını ve gelecek kuşaklara da aktarılmasını sağlamak olarak ifade edilebilir (Karabıçak ve Özdemir, 2015, s. 44).

Sürdürülebilirlik kavramının gelişimine bakıldığında, kavramın ilk olarak makro düzeyde ülkelerin ekonomik gelişmişliğini ifade etmek amacıyla kullanıldığı, daha sonra ise mikro düzeyde işletmelerin kurumsal sürdürülebilirliğini ifade etmek için kullanıldığı görülmektedir (Önder, 2017, s. 939). Kurumsal sürdürülebilirlik, ilk zamanlar işletmelerin çevreye karşı daha duyarlı davranmalarını ve çevre üzerindeki negatif etkilerini azaltmalarını gerektiren bir yaklaşım olarak görülmüş ancak bu bakış açısı süreç içerisinde yerini "sürdürülebilirliğin üç ayă̆ı" ş̧eklinde ifade edilen ve işletmelerin ekonomik, toplumsal ve çevresel amaçlarının bir denge içerisinde gözetilmesi gerektiğini savunan yaklaşıma bırakmıştır. İlk defa 1997 yılında John Elkington tarafından ortaya atılan "triple bottom line" kavramiyla, geleneksel muhasebe uygulamalarına işletmelerin finansal performans bilgileriyle birlikte toplumsal ve çevresel performanslarına ilişkin bilgilerin de dahil edilmesi gerektiği dile getirilmiştir. Buna göre, söz konusu alanlardan herhangi birinin ihmal edilmesi, işletmelerin tüm faaliyetlerinin ve dolayısıyla kurumsal sürdürülebilirliklerinin tehlikeye atılması anlamına gelecektir (Aras ve Sarığlu, 2015, s. 24).

Sürdürülebilirlik konusunda işletmelere rehberlik etmek ve sürdürülebilirlik raporlaması için küresel boyutta ortak bir dil oluşturmak amacıyla 1997 yılında bağımsız bir uluslararası kuruluş olarak Küresel Raporlama Girişimi (Global Reporting Initiative-GRI) kurulmuştur. GRI, çok paydaşlı ve bağımsız bir kuruluş olarak dünya çapında hem işletmelerin şeffaf ve hesap verebilir olmalarını sağlamak üzere sürdürülebilirlik raporlaması yapmalarını teşvik etmeyi hem de bu raporların güvenilir, tutarlı ve karşılaştırılabilir olmalarını sağlamayı amaç edinmektedir. $\mathrm{Bu}$ amaçla GRI, sürdürülebilirlik raporlaması yapmak isteyen işletmeler için 2000 y1lında G1 olarak isimlendirilen sürdürülebilirlik raporlamas kılavuzunu yayımlamış, daha sonra söz konusu kılavuzu 2002 yılında güncelleyerek G2 olarak, 2006 y1lında G3 ve 2013 yılında G4 olarak işletmelerin kullanımına sunmuştur (GRI, 16.09.2021). Buna ek olarak, işletme paydaşlarının haklarını ve çıkarlarını korumak amacıyla 1999 yılında OECD tarafindan adillik, şeffaflık, sorumluluk ve hesap verebilirlik çerçevesinde belirlenen kurumsal yönetim ilkeleri yayımlanmıştır. Böylelikle GRI tarafından yayımlanan sürdürülebilirlik raporlaması kılavuzları ve OECD tarafından belirlenen kurumsal yönetim ilkeleri ile işletmelerin paydaş teorisi kapsamında sürdürülebilir yapı kazanmaları amaçlanmıştır (Kevser, 2020, s. 4232).

Sürdürülebilirlik kavramında olduğu gibi kalkınma kavramına da toplumların gelişme süreçlerine bağlı olarak farklı dönemlerde farklı anlamlar yüklenmiştir. 
Bazen aynı zaman dilimi içerisinde farklı anlamlarda kullanımı da söz konusu olmuştur. Kalkınma kavramı, kimi zaman sanayileşmeyi, modernleşmeyi, ekonomik büyümeyi, ilerlemeyi ve yapısal değişimi ifade etmek için veya doğrudan onların yerine kullanılmıştır. $\mathrm{Bu}$ durum da kavramın anlamının kaymasına neden olmuş ve içeriğinin yeterince açık ve anlaşılır olmamasına sebebiyet vermiştir (Yavilioğlu, 2002, s. 59).

Genel bir anlatımla kalkınma, birçok ülkenin erişmek istediği temel amaç ve bununla birlikte ekonomik ve ekonomik olmayan bazı değişkenlerde radikal değişikliklere neden olan bir süreç olarak ifade edilebilir. Kalkınma kavramının yaygın şekilde kullanılmaya başlandığı dönem II. Dünya Savaşı sonrasına denk gelmektedir. Buna karşın önceki dönemlerde iktisat biliminde kalkınma kavramı yerine "ilerleme" kavramının kullanıldığı da bilinmektedir. Bu bakımdan Adam Smith'in kullandığı "maddi ilerleme" ve John Stuart Mill'in kullandığı "ekonomik ilerleme" terimleri kalkınma kavramı ile özdeşleştirilebilir (Mıhçı, 1996, s. 65). Bilhassa II. Dünya Savaşı sonrası meydana gelen gelişmeler ile bağımsızlıklarına yeni kavuşan birçok ülkenin, geç kaldıkları sanayileşme süreciyle ilgili olarak ciddi atılımlar yapmaları, bu dönemde kalkınma olgusunun sanayileşmeyle özdeşleştirilmesine sebebiyet vermiştir (İlkin, 1988, s. 1'den akt. Yayl1, 2012, s. 154).

Dinamik ve karmaşık bir süreç olan kalkınma olgusu, yalnızca bir unsura bağlanarak açıklanamayacağı için, kalkınmaya dair göstergeler de çeşitlilik arz etmektedir. Bu bakımdan kalkınmayı salt ekonomik büyüme ile açıklamak olası değildir. Toplumun hayat standartlarının yükselmesi, sosyal gelişmenin sağlanması ve adil gelir dağılımı gibi unsurlar da kalkınmanın önemli göstergelerindendir. Buna ek olarak, kalkınmanın sağlanması kadar bunun sürdürülebilir olması da önem kazanmıştır. Bu bakımdan kalkınmanın, ekonomik büyümeyle birlikte sosyal ve kültürel gelişmeye ve çevrenin korunmasına da katkıda bulunması, dahası bunu sürdürülebilir hâle getirmesi gerekmektedir (Ataçay, 2020, s. 443). Bu açıdan bakıldığında sürdürülebilir kalkınma, Sanayi Devrimi'yle başlayan ve günümüzde de devam etmekte olan, hammaddenin işlenerek nihai ürüne dönüştürülmesi sürecinin, sadece ekonomik faydayı önceleyen ve uzun dönemli sosyal ve ekolojik gelişmenin önünü tıkayan sistematiğine alternatif olarak ileri sürülen bir kavram (Akgül, 2010, s. 135) olarak ifade edilebilir.

Sürdürülebilir kalkınma kavramı, günümüzde kullanılan anlamıyla ilk olarak, Dünya Çevre ve Kalkınma Komisyonu tarafından 1987 yılında yayımlanan Brundtland Raporu'nda "gelecek nesillerin ihtiyaçlarını karşılama yeteneğinden ödün vermeden, bugünün ihtiyaçlarını karşılayan kalkınma" şeklinde ifade edilmiştir (UN, 1987). Başka bir anlatımla sürdürülebilir kalkınma kavramı, insan sağlığının ve doğal dengenin korunarak, doğal kaynakların rasyonel bir biçimde kullanılması ve sonraki nesillere iyi bir doğal, fiziksel ve sosyal çevre bırakılması 
yaklaşımıdır. Bu şekilde bir yaklaşım, küresel çapta kalkınma çabalarının her aşaması için iktisadi, siyasi ve sosyal politikaların çevre politikalarıyla beraber yürütülmesini gerekli kılmaktadır (Altunbaş, 2003, ss. 103-104).

Sürdürülebilir kalkınma olgusunun ortaya çıkma sürecine bakıldığında gerek Klasik İktisat Görüşü'nün gerekse Keynesyen İktisadi Görüş'ün hâkim olduğu dönemlerde ekonomik büyümeye, sanayileşmeye ve üretim artışına öncelik verildiği; buna karşın doğal kaynakların bilinçsizce kullanımının, çevresel kirliliğin, iklim değişikliğinin, canlı türlerinin azalmasının, ormanların yok edilmesinin ve yoksulluğun yaygınlık kazanmasının görmezden gelindiği anlaşılmaktadır. İnsan ile doğal çevre arasındaki ilişside, dengenin sürekli olarak çevre aleyhine bozulması ve doğal çevrenin kendini yenileyebilme kapasitesinin azalmaya başlaması, 1960'lı yıllara gelindiğinde fark edilmeye başlamıştır. 1970'li yıllardan itibaren ise sürdürülebilir kalkınma konusunda uluslararası gündem oluşmaya başlamıştır (Tıraş, 2012, ss. 61-62).

Sürdürülebilir kalkınma kavramının, ekonomik, sosyal ve ekolojik olmak üzere üç tane boyutu bulunmaktadır. Bu kapsamda kavramın ekonomik boyutu hem bireysel hem de toplumsal ihtiyaçların etkin bir biçimde giderilmesini ve buna bağlı olarak tüketim alışkanlıklarının da yeniden gözden geçirilmesini gerekli kılmaktadır. Kavramın sosyal boyutu hem yerelde hem de küresel ölçekte sosyal dayanışmayı ve adil paylaşımı gerektirmektedir. Sürdürülebilir kalkınmanın ekolojik boyutu ise doğal dengenin uzun vadeli olarak güvenceye alınmasını, bu kapsamda tüketimin kontrol altında tutulmasını, üretim süreçlerinde öncelikle yenilenebilir kaynakların kullanılmasını ve doğanın kendini yenileyebilmesine izin verilmesi gerektiğini zorunlu kılmaktadır (Ergün ve Çobanoğlu, 2012, s. 119). Söz konusu boyutlar kapsamında sürdürülebilir kalkınmanın çeşitli hedefleri Şekil 1'de özetlenmiştir.

Şekil 1 incelendiğinde, sürdürülebilir kalkınmanın üç boyutu olan ekonomi, toplum ve çevrenin birbiriyle belirli noktalarda kesiştikleri dolayısıyla birbirlerine bağımlı oldukları anlaşılmaktadır. Sürdürülebilir kalkınmanın hedeflerine bakıldığında, ekonomik hedeflerin büyüme, verimlilik ve istikrar olduğu; sosyal hedeflerin tam istihdam, eşitlik, güvenlik, eğitim ve sağlık imkânlarının iyileştirilmesi, toplumsal hayata katılımın artırılması ve kültürel kimliklerin korunması olduğu; çevresel hedeflerin ise insanlar için sağlıklı bir çevreye sahip olma, yenilenemeyen doğal kaynakların korunması ve yenilenebilir doğal kaynakların da rasyonel bir şekilde kullanılması olduğu görülmektedir. Söz konusu hedeflere ulaşmaya çalışılırken bazılarının diğerlerine tercih edilmemesi gerekmektedir. Zira sürdürülebilir kalkınmanın gereği olarak ekonomik hedeflere ulaşmaya çalış1lırken toplumun ve çevrenin de göz önünde bulundurulması gerekmektedir. 


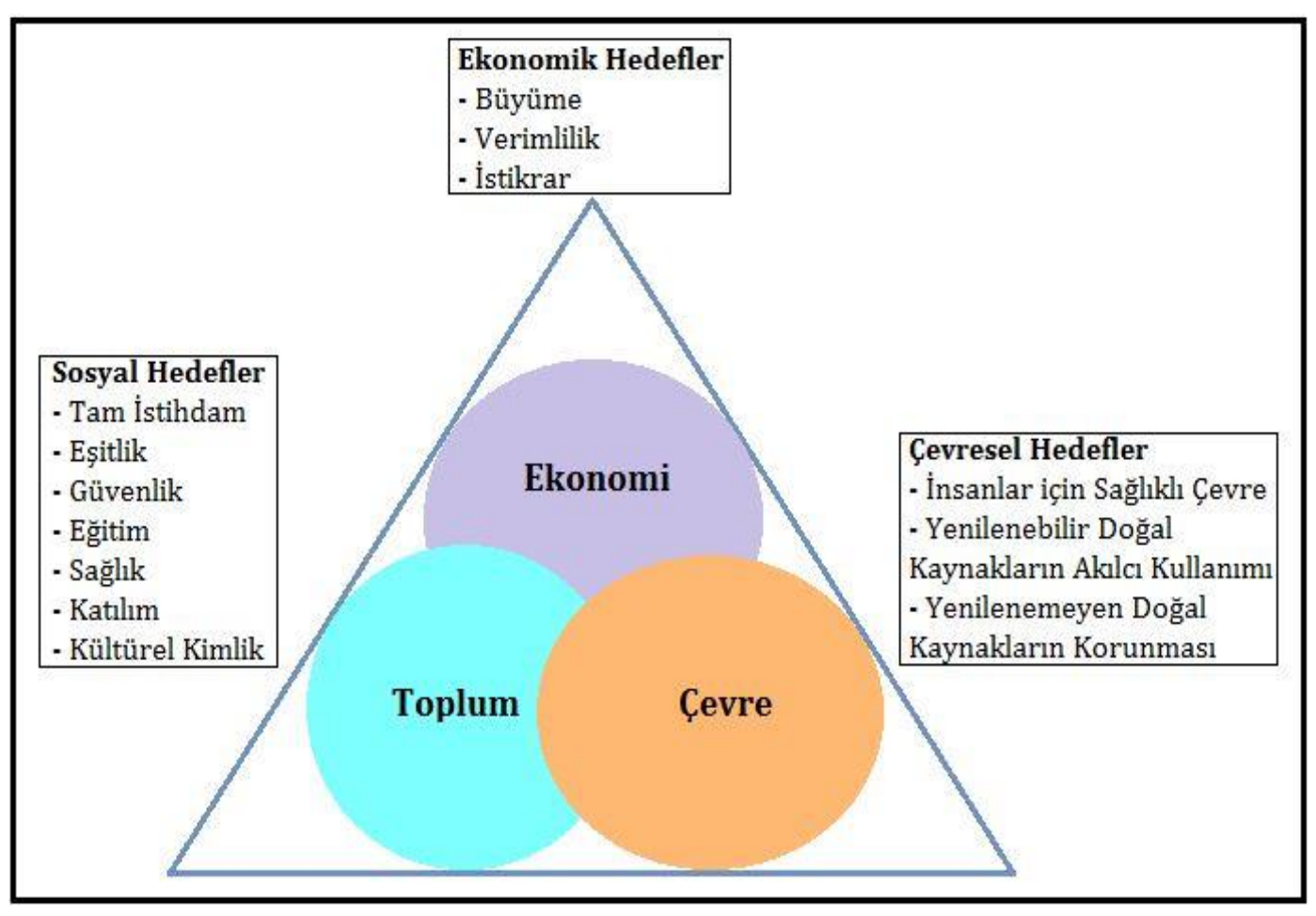

\section{Şekil 1: Sürdürülebilir Kalkınmanın Hedefleri}

Kaynak: Soubbotina, 2004, s. 10’dan uyarlanmıştır.

Sürdürülebilir kalkınmanın üç boyutunu Şekil 1'deki gibi birbirleriyle belirli noktalarda kesişen kümeler şeklinde değil de bunların birbirini kapsayan ve aralarındaki bağımlılığı daha belirgin biçimde gösteren Şekil 2'deki gibi modellenmesi gerektiğini ifade eden görüşler de mevcuttur.

Giddings, Hopwood ve O’Brien (2002)'e göre, sürdürülebilir kalkınma boyutlarının Şekil 1'deki gibi tasvir edilmesi, bütünden ziyade parçalar üzerinde yoğunlaşmaya sebebiyet verebilmekte ve boyutlardan birinin diğerlerine göre öncelenmesine neden olabilmektedir. Nitekim politik gerçeklik genellikle ekonomiye öncelik vermekte, çevre ile toplumu ise doğal ve beşerî kaynakların temin edileceği yerler olarak görmektedir. Oysa gerçek durum, ekonominin toplum ve çevre ile iç içe olduğunu hatta çevre olmadan toplumun var olamayacağını, toplum olmadan da ekonomiden bahsedilemeyeceğini göstermektedir. $\mathrm{Bu}$ bakımdan modelde ekonomiyi merkeze almak onun, diğer boyutların etrafında döndüğü merkez olarak görülmesi gerektiği anlamına gelmemekte, aksine diğerlerinin alt kümesi ve onlara bağımlı olduğu anlamına gelmektedir. 


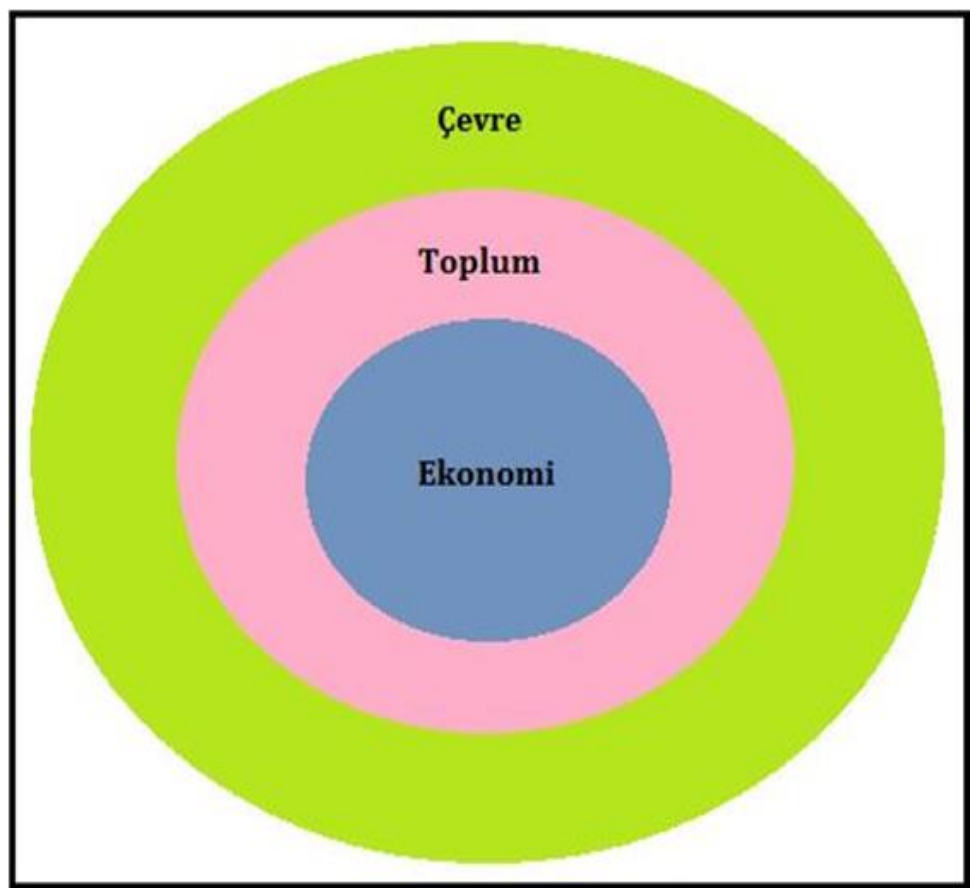

\section{Şekil 2: Sürdürülebilir Kalkınma Boyutlarına Alternatif Yaklaşım}

Kaynak: Giddings, Hopwood ve O’Brien, 2002: s. 192'den uyarlanmıştır.

Günümüz iş dünyasının koşullarını belirleyen küresel ekonomi kavramı, liberalizm, globalleşme ve sürdürülebilirlik gibi özellikleriyle işletmelerin faaliyetleri, ihtiyaçları ve toplumun işletmelerden olan beklentileri üzerinde etkili olmaktadır. Bunun yanı sira internet ve sosyal medya platformlarının yaygınlaşması neticesinde, işletmelerin sadece hissedarlarına değil bütün paydaşlarına karşı sorumlu davranmaları ve faaliyetleriyle ilgili olarak tüm toplumu şeffaf bir şekilde bilgilendirmeleri talep edilmeye başlanmıştır. Bu beklentiyle beraber ișletmelerin hem paydaşlarına hem de genel olarak topluma karşı sorumlulukları çeşitlenmiştir. Dinamik ve rekabetin yüksek olduğu bir piyasada ayakta kalmak isteyen işletmelerin, toplumun gerek finansal gerekse sosyal ve çevresel taleplerini görmezden gelerek başarılı olmaları mümkün olmayacaktır. $\mathrm{Bu}$ bakımdan işletmeler faaliyette bulunurken ve stratejilerini oluştururken toplumsal ve çevresel faktörleri göz önünde bulundurmalı ve varlıklarının sürdürülebilirliği için de gerek finansal gerekse sosyal ve çevresel faaliyetlerini şeffaflık ilkesi kapsamında tüm paydaşlarıyla paylaşmalıdır. Bu noktadan hareketle geleneksel finansal raporlamanın tarihi veriler kullanılarak yapılması, sosyal ve çevresel konularda yeterince bilgi içermemesi, süreç içerisinde bu konularda paydaşlara ihtiyaç duydukları bilgileri sunan sürdürülebilirlik raporlamasının ve son olarak entegre raporlamanın ortaya çıkmasını sağlamıştır (Battal, 2018, s. 394). 


\section{Entegre Raporlama Kavramı}

Entegre raporlama, işletme faaliyetlerinin finansal ve sürdürülebilirlik bilgilerini kapsayan, bu bilgiler arasındaki ilişkileri ortaya koyan, kısa, orta ve uzun vadede işletmelerin değer yaratma süreçlerine odaklanan, işletmelerin gelecekte karşılaşabilecekleri riskleri ve firsatları dikkate alan, işletmelerin iş modellerini ve stratejilerini yansıtan kapsamlı ve bütünsel bir kurumsal raporlama yaklaşımıdır. Entegre raporlama, başta yatırımcılar olmak üzere, tüm paydaşlara işletmenin finansal ve sürdürülebilirlik bilgileri arasında bağlantı kurma, işletmenin süreçlerini ve stratejilerini anlama, işletmenin karşılaşabileceği riskleri ve fırsatları ölçülebilir bir şekilde görme fırsatı sağlamaktadır. Entegre raporlama aracılığıyla işletmenin geçmiş performansına dair bütünsel bir fotoğraf ortaya konulduğu gibi, işletmenin gelecekteki hedeflerine nasıl ulaşacağı, nasıl değer yaratacağı ve sürdürülebilirliğini nasıl sağlayacağı da açıklanmaktadır (Öztürk, 2019, s. 3). Bu bakımdan işletmelerin finansal ve finansal olmayan bilgilerini bir arada sunan entegre raporlama kavramı, finansal ve sürdürülebilirlik raporlarının basitçe birleşiminden oluşan bir dokümandan fazlasını ifade etmektedir (Krzus, 2011, s. 271).

Kurumsal raporlamanın yıllar içinde geçirmiş olduğu değişimin son safhası olan entegre raporlama, aynı zamanda kurumsal raporlama uygulamalarının gelmiş olduğu son seviyeyi ve bu uygulamaların geleceğini temsil etmektedir (Yıldırım ve Uzun Kocamış, 2018, s. 37).

Uluslararas1 Entegre Raporlama Konseyi (International Integrated Reporting Council IIRC)'ne göre entegre raporlama, “Bir kuruluşun stratejisinin, kurumsal yönetiminin, performansının ve beklentilerinin kuruluşun diş çevresi bağlamında kısa, orta ve uzun vadede değer yaratmayı nasıl sağlayacağının kısa ve öz bir şekilde bildirilmesidir." (IIRC, 2013, s. 7). King III Raporu (King Report on Governance for South Africa 2009)'na göre ise entegre raporlama, işletme performansının hem finansal hem de sürdürülebilirlik açısından bütünsel ve entegre bir sunumudur (Institute of Directors Southern Africa, 2009, s. 108).

Entegre raporlamanın öncüsü kabul edilen IIRC'nin eski başkanı Mervyn King'e göre; entegre raporlama, bir işletmenin kazandığı paranın miktarıyla değil, o parayı nasıl kazandığıyla ilgilenir (TKYD, 2014, s. 18). King'e göre; mevcut finansal raporlama modeli işletmelerin sadece finansal durumuna odaklanırken; entegre raporlama, işletmelerin kâr elde ederken sosyal, çevresel ve finansal bakımdan piyasa üzende bıraktığı etkiye yoğunlaşır. Böylece işletmelerin faaliyetlerini uzun vadede nasıl sürdüreceğini ortaya koyarak, işletme paydaşlarının işletmeyle ilgili rasyonel kararlar almalarına imkân sağlamaktadır (Kaya, 2015, s. 115).

Entegre raporlamanın geçmişine bakıldığında, Güney Afrika Cumhuriyeti'nin tam demokrasiye geçiş yaptığı 1994 yılına kadar dayandığı görülmektedir. O yıl 
başkan seçilen Nelson Mandela, kamuoyunun ülkedeki şirketlere olan güvenini artırabilmek amacıyla eski bir Yüksek Mahkeme yargıcı olan Mervyn King'i kurumsal yönetişim alanında çalışmalar yapacak bir komite kurması ve bu komiteye rehberlik etmesi için görev vermiştir (WBCSD, 2014, s. 6). Kurulan komite, 1994 yılında Güney Afrika'da en yüksek kurumsal yönetim standartlarını teşvik etmek amaciyla, King I (King Report on Corporate Governance) olarak bilinen raporu yayımlamıştır. Yayımlandığı dönemde iyi amaçlara hizmet etmiş olmasına rağmen, gelişen küresel ekonomik ortam ve yasal düzenlemeler King I'in güncellenmesini gerekli kılmış ve 2002 yılında King II Raporu yayımlanmıştır. King II Raporu'nda işletmelerden, faaliyetlerinin ekonomik, çevresel ve toplumsal etkilerini açıklamaları istenmiştir (Cliffe Dekker Attorneys, t.y., s. 2).

Etkilerini tüm dünyada gösteren 2008 yılı mali krizi geleneksel raporlamanın, uzun ve karmaşık yapısına rağmen, artık riskleri ele alma konusunda yeterli olmadığını göstermiştir. Bu bağlamda, 2009 yılında yatırımcılar, işletmeler ve kamuoyu arasında güven tesis etmek amaciyla, işletmelerin hem finansal hem de sürdürülebilirlik açısından performanslarının bütüncül bir sunumu olan, entegre raporlama kavramının yer aldığı King III Raporu yayımlanmıştır. King III Raporu'ndan sonra, hisseleri Johannesburg Menkul Kiymetler Borsas1 (Johannesburg Stock Exchange-JSE)'nda işlem gören şirketlerin 1 Mart 2010 tarihinden itibaren entegre raporlama yapmaları, yapmiyorlarsa sebebini açılamaları zorunlu hale getirilmiştir (WBCSD, 2014, s. 6). Böylece entegre raporlamanın, hisseleri borsada işlem gören işletmelere zorunlu kılındığı ilk ülke Güney Afrika olmuştur. Güney Afrika'dan sonra Fransa, Danimarka ve Portekiz gibi bazı ülkeler de işletmelerden birtakım finansal olmayan bilgilerini açıklamayı zorunlu hale getirmiş̧lerdir (Aras ve Sarıŏlu, 2015, s. 41).

Güney Afrika'da bu gelişmeler yaşanırken, 17 Aralık 2009 tarihinde Galler Prensi, Küresel Raporlama Girişimi (Global Reporting Initiative-GRI)'ne ve Uluslararası Muhasebeciler Federasyonu (International Federation of Accountants-IFAC)'na kurumsal raporlamaya uluslararası bağlantılı ve entegre bir yaklaşım geliştirmesi amacıyla "Uluslararası Entegre Raporlama Konseyi" (IIRC)'ni kurmaları için çağrıda bulunmuştur. Nitekim IIRC, bu işlevi yerine getirmek amacıyla 2010 yılında, paydaşları sivil toplum kuruluşları, yatırımcılar, muhasebeciler, yasal düzenleyiciler, akademisyenler ve standart belirleyicilerden oluşan uluslararası bir koalisyon olarak kurulmuştur (Morros, 2016, ss. 338-339).

IIRC gerek kamu sektöründe gerekse özel sektörde kurumsal raporlama biçimi olarak entegre raporlamanın kullanıldı̆̆ 1 ve kurumlarda entegre düşüncenin yerleştiği bir dünyayı vizyonu olarak belirtmiştir (IIRC, 2013, s. 2). İşletmelere entegre raporlama konusunda yol gösterecek ve uluslararası geçerliliği olan bir raporlama çerçevesi oluşturmayı amaç edinen IIRC, 2011 yılında bir taslak yayımlayarak, dünya genelinden kurum, kuruluş ve akademisyenlerin de 
görüşlerini almış ve 2013 yılında çerçevenin bitmiş hâlini yayımlamıştır. Entegre raporlama yapan işletmeler, raporlarını hazırlarken bu çerçeveyi kılavuz olarak kullanmaktadır (Aras ve Sarığlu, 2015, s. 42).

\subsection{Entegre Raporlamanın Amacı ve İçeriği}

Dräger (2014)'a göre entegre raporlamanın temelinde, işletmelerin değerini çok sayıda faktörün belirlediğine dair algı yer almaktadır. Bu faktörlerden bazıları finansal ya da somut nitelikte olup, işletmelerin finansal tablolarında kolayca gösterilebilirken (örneğin; nakit, stoklar, maddi duran varlıklar vs.), bazılarının somut bir varlıkları söz konusu olmayıp, finansal tablolarda gösterilmeleri olanaksızdır (örneğin; enerji güvenliği, entelektüel sermaye, rekabet durumu vs.). Entegre raporlama, işletmelerin kısa, orta ve uzun dönemde değer yaratmak için sahip oldukları maddi ve maddi olmayan tüm kaynakları nasıl kullandıklarını, aralarındaki ilişkilerle birlikte ortaya koymaktadır.

İşletmelerin uzun vadeli değer yaratma kabiliyetlerine odaklanan entegre raporlamanın başlıca amaçlarını aşağıdaki gibi sıralamak mümkündür (IIRC, 2013, s. 2):

- Sermayenin daha etkili bir şekilde tabana yayılması için hissedarlara sunulan bilginin kalitesini artırmak.

- Kurumsal raporlamayı daha bütüncül ve verimli bir perspektif ile yapmak.

- Sermaye türleri (finansal sermaye, fikri sermaye, beşerî sermaye, doğal sermaye vs.) için hesap verebilirliği güçlendirmek ve bu sermaye türleri arasındaki bağımlılığın anlaşılmasını sağlamak.

- Amacı kısa, orta ve uzun vadede değer yaratmak olan entegre düşünce sürecini desteklemek.

İşletmeler, entegre raporlama aracılığıyla faaliyetlerinin ekonomik, toplumsal ve çevresel ilişkilerini ortaya koyarken, sadece geçmiş faaliyet sonuçlarını değil, gelecekleriyle ilgili uzun vadeli planlamalarını da ifade etme imkânı bulabilmektedirler. Entegre raporlama ile işletmelerin tedarik zinciri boyunca karşılaşabilecekleri finansal ve finansal olmayan riskler ve firsatlar daha iyi değerlendirilebilmekte ve söz konusu risklerin nasıl ele alındığ açıklanabilmektedir (Aras ve Sarıoglu, 2015, s. 43).

İyi bir entegre rapor, menfaat gruplarının birbirinden farklı çıkarlarına ilişkin bilgiler sunduğu gibi; işletmenin faaliyet gösterdiği çevre, iş modeli, sahip olduğu sermaye türleri, stratejisi, karşı karşıya kaldığı risk ve fırsatları, performansı ve geleceğe ilişkin beklentileri hakkında da anlaşılır bir dille, kısa ve öz bilgiler vermelidir. Entegre rapor, bir taraftan işletmenin cari dönemde gerçekleştirdiği faaliyetlerle ilgili en önemli konulara odaklanırken diğer taraftan işletmenin geleceğine ilişkin de bilgiler sunar. Çünkü entegre raporlamayı diğer raporlama türlerinden ayıran en belirgin özelliği gelecek odaklı olmasıdır. Entegre 
raporlamanın bu özelliği, işletmenin gelecekteki değer yaratma yeteneği ve karşılaşabileceği risk ve fırsatlar hakkında bilgi kullanıcılarına fikir vermesi bakımından önemli görülmektedir (King ve Roberts, 2017, s. 91).

\subsection{Entegre Raporlamanın Faydaları}

Entegre raporlama yapmanın işletmelere ve işletme çıkar gruplarına sağladığı (ya da sağlayacağı düşünülen) faydaları aşağıdaki gibi maddeler halinde sıralamak mümkündür (Kanzer, 2010, ss. 46-47; IIRC, 2011, s. 21; Çalkıvik, 2013, s. 74; Aras ve Sarıoglu, 2015, ss. 46-49; Kaya, 2015, ss. 123-124; Bhasin, 2017, s. 21):

İşletmeler için;

- Çok sayıda rapor yerine entegre bir raporun yayımlanması işletmenin raporlama maliyetlerini azaltabilir.

- Entegre raporlama, işletmenin hem iç hem de dış paydaşlarıyla daha güçlü iletişim kurmasına yardımcı olur.

- Entegre raporlama, sürdürülebilirlik konusunun işletmenin yalnızca bir departmanını değil tüm işletmeyi ilgilendirdiğini ortaya koyar.

- Entegre raporlama düzgün yapıldığı takdirde, işletmenin hem finansal hem de sürdürülebilirlik performansını artırdığı gibi bunların birbiriyle uyumlu olmasını da sağlar.

- İşletme tarafindan yayımlanan iç ve dış raporların tutarlı olmasını sağlar.

- İşletmenin iyi ve kötü taraflarının birlikte paylaşılması, işletmeye güven duyulmasını sağlayacaktır.

- İşletmelerin marka değerini artırıp, itibar riskini azaltır.

- İşletmelerin finansman ihtiyaçlarını daha kolay giderebilmelerine yardımcı olarak, sermaye maliyetlerini azaltabilir.

- Azalan maliyetler, artan marka değeri ve verimlilik ile işletmeler rekabet avantaj1 elde edebilir.

- Yönetimin riskleri ve firsatları daha iyi değerlendirmesini sağlar.

- Entegre raporlama, işletmelerin mevcut sistem ve süreçlerinde değişiklikler yaparak, işletmelerin nasıl sürdürülebilir değer yarattıklarını daha iyi anlamalarını sağlar.

- İşletmeler entegre raporlama aracılığıyla sürdürülebilir kalkınmanın iş modellerinin merkezinde yer aldığını gösterebilir.

- Entegre raporlama, işletmelerin kendi hikayelerini daha iyi bir şekilde anlatabilecekleri bir araç olabilir.

\section{Yatırımcılar için;}

- Çoğu analistin yalnız başına göz ardı ettiği sürdürülebilirlik raporu, entegre raporlama sayesinde, finansal bilgilerle olan bağı kurulup bunların kullanımına sunulabilir. 
- Yatırımcıların işletmenin uzun vadeli potansiyelini daha iyi anlamalarını sağlar.

- Sadece finansal değil sosyal ve çevresel kriterlerin de göz önünde bulundurulduğu bir finansman piyasasının ortaya çıkmasına yardımcı olabilir.

- İşletme ile pay sahipleri arasında daha iyi iletişim kurulmasını sağlayarak, karşı1ıklı yüksek düzeyli bir güven ortamı tesis edebilir.

\section{Diğer çıkar grupları için;}

- İşletmenin tüm paydaşlarıyla daha iyi iletişim kurmasını sağlar.

- Paydaşların işletmeler ile ilgili daha doğru değerlendirmeler yapmalarına yardımci olur.

- Paydaşların ihtiyaç duyduğu gibi kısa ve öz olarak hazırlanan entegre rapor, bilgi kirliliğine neden olmaz.

- İşletmenin tedarikçileriyle olan ilişkisini ve iş birliğini artırır.

- Toplumun sürdürülebilirlikle ilgili farkındalı̆ğını artırır.

3.3. Sürdürülebilir Kalkınma Açısından Entegre Raporlama Uygulamasının Değerlendirilmesi

Günümüzde sürdürülebilir kalkınmanın önündeki en büyük engeller güvenlik, çalışma şartlarıyla ilgili çeşitli sosyal sorunlar, sağlık ve eşitlik gibi konular olmaktadır. İşletmelerin en açık toplumsal rolleri, istihdam yaratmaları ve bu sayede hem ekonomik hem de sosyal olarak kalkınmaya katkı sağlamalarıdır (Aras ve Sarığlu, 2015, s. 26). Ancak toplumun işletmelerden beklentisi ekonomik, yasal ve etik sorumluluklarının ötesinde, işletmelerin toplumsal fayda için gerçek bir çaba içerisinde olmalarıdır. Söz gelimi, çalışanlara rahatça geçinebilecekleri ücretler verilmesi, daha temiz bir çevre, vahşi yaşamın ve habitatın korunması, satılan ürünlerin makul bir şekilde fiyatlandırılması gibi talepler toplumun işletmelerden olan beklentileri arasında yer almaktadır (Banik, 2015, s. 162). Bu beklentilere koşut olarak işletmeler de hem faaliyetlerinin hem de uzun vadeli kârlılıklarının sürdürülebilirliğinin sosyal adalete ve çevrenin korunmasına bağlı olduğunun farkına varmış durumdadır (GRI, 2014, s. 3).

Salt ekonomik unsurları dikkate alarak elde edilen büyümenin artık yalnız başına dünyadaki temiz su, sağlık ve eğitim hizmetlerine ulaşım ve yoksulluk gibi problemleri gidermediği görülmüştür. Küresel nüfusun hızlı artışıyla beraber artan tüketim ve buna bağlı olarak azalmakta olan doğal kaynaklar, söz konusu kaynakların daha adaletli ve etkin bir şekilde paylaşılmasını sağlayabilecek sürdürülebilir bir ekonomik modeli zorunlu hâle getirmiştir. Ekonomik sürdürülebilirlik olarak isimlendirilen söz konusu model, işletmelerin kâr elde etme amaçlarını gerçekleştirirken, faaliyetlerinin içinde bulundukları çevreye ve topluma zarar vermemeleri şeklinde ifade edilmektedir. Sürdürülebilirlik ve kârlılık kimi zaman birbirleriyle çatışan amaçlar olarak ele alınsa da tersine 
bunların birbirlerini destekleyen kavramlar olarak değerlendirilmesi gerekmektedir (Aras ve Sarığlu, 2015, ss. 24-25).

Geçmişte işletmelerin varlıklarını devam ettirebilmeleri, faaliyetlerinin devamlılığına bağlı iken, günümüzde bu durum işletmelerin insana ve çevreye olan duyarlılığına ve iyi kurumsal yönetim uygulamalarına bağlı hâle gelmiştir. Küresel ölçekte artık işletmelerin hem günümüz insanlarına hem de gelecek kuşaklara karşı sorumlu davranmaları gerektiği konusunda bir bilinç oluşmuştur. Gelecek kuşaklara karşı sorumlu davranma hem dünyayı daha yaşanabilir hâle getirmekte hem de çevrenin korunarak, insanların yaşam standartlarının yükselmesine etki etmektedir. Bu sebeple, işletmelerin faaliyetlerinin sadece finansal boyutlarını değil toplumsal ve ekolojik boyutlarını da göz önünde bulundurmaları gerekmektedir. Nitekim kısa dönemli ve salt kâr odaklı yaklaşımların uzun vadede sürdürülebilir olmadıkları ve böyle yaklaşımların toplum tarafından da kabul görmeyecekleri aşikârdır. Bireysel menfaatlerin yerine toplumsal faydanın öncelendiği bu dönemde, işletmelerin değeri de toplumsal faydaya yaptıkları katkıya göre belirlenmektedir. Ayrıca paydaşların işletme faaliyetlerinin finansal bilgilerinin yanında finansal olmayan bilgilerini de talep etmeleri, işletmelerin sürdürülebilirlik konusunda çeşitli stratejiler oluşturmaları, bu stratejileri iş süreçlerine entegre etmeleri ve sürdürülebilirlik konusunda raporlama yapmaları bakımından bir baskı unsuru olmaktadır. Bu nedenlerden ötürü işletmeler, ekonomik, toplumsal, ekolojik ve kurumsal yönetimle ilgili unsurların bir bütün olarak gözetildiği ve bu unsurlara bağlı risklerin ve firsatların etkili bir şekilde yönetildiği kurumsal sürdürülebilirliği benimsemektedirler. (Aksoy, 2019, s. 325).

Muhasebenin temel kavramlarından biri olan işletmenin sürekliliği kavramı, işletme faaliyetlerinin sahip ya da sahiplerinin yaşam sürelerine bağlı olmaksızın sürdürüleceğini ifade etmektedir. Başta yatırımcılar olmak üzere, paydaşlar işletmeyle ilgili karar alırken veya işletmenin sürdürülebilirliğini değerlendirirken finansal bilgilerin yanında en az onlar kadar değerli finansal olmayan bilgileri de kullanmak isterler. Özellikle son yıllarda yalnızca rapor edilmiș kârlılık oranları değil sosyal ve çevresel faktörler de dikkate alınarak, işletmelerin gelecekteki durumları görülmek istenmekte ve böylelikle işletmelerin sürdürülebilirlikleri test edilmeye çalışılmaktadır. Paydaşların bu ihtiyaçları kapsamında dünyadaki kurumsal raporlama uygulamalarının gelişimine bakıldığında, gelinen nihai noktanın entegre raporlama olduğu görülmektedir (Gücenme Gençoğlu ve Aytaç, 2016, s. 52).

Entegre raporlama, küresel ekonominin, iş dünyasının, piyasa koşullarının ve iş yapma biçimlerinin değişmesi neticesinde ortaya çıkan ve işletmelerle ilgili bütünsel bir yaklaşım sunan çağdaş bir raporlama şeklidir. İş dünyasında yaşanan değişme ve gelişmeler, kamu sektörü özel sektör ayrımı gözetilmeksizin işletme paydaşlarının bilgiye olan ihtiyacını ve bilgi talebini de değiştirmiştir. $\mathrm{Bu}$ 
bakımdan işletme paydaşları artık sadece finansal bilgi ile yetinmemekte aynı zamanda işletme faaliyetlerinin sürdürülebilirlik boyutu ile ilgili bilgileri de talep etmektedirler. Tarihi verilerle oluşturulan finansal bilgi her zamanki önemini korumakla birlikte yalnız başına işletmenin geçmiş ve gelecek durumuyla alakalı bir perspektif sunamamaktadır. İşletmenin geleceğine dair paydaşlara bir perspektif sağlayan entegre raporlama, işletmenin kısa, orta ve uzun vadeli olarak hem kendisi hem de paydaşları için nasıl değer yaratacağını da ortaya koymaktadır. Bunun yanı sıra entegre raporlama, kurumsal yönetim ilkelerine uygun şekilde işletmelerin şeffaflığını ve hesap verebilirliğini artırmakta; işletmelerin kendilerini daha iyi değerlendirebilmelerine imkân vererek, güçlü ve zayıf taraflarını, fırsat ve tehditlerini daha iyi analiz edebilmelerini sağlamaktadır. $\mathrm{Bu}$ bakımdan entegre raporlar ile aralarında etkileşim kurularak sunulan finansal ve sürdürülebilirlik bilgileri, işletme paydaşlarının daha isabetli kararlar almalarını sağlayabilmektedir (Kevser, 2020, s. 4232).

Kurumsal sürdürülebilirlik yaklaşımıyla hareket edip, bunu karar alma süreçlerine entegre eden işletmelerin uzun dönemde maliyetlerinin düştüğü, verimlilik ve kârlılıklarının yükseldiği bununla birlikte kurumsal itibarlarının ve marka değerlerinin arttı̆g bilinmektedir. Kurumsal sürdürülebilirlik yaklaşımı her ne kadar kısa dönemde AR-GE, personel eğitimi ve risk yönetimiyle ilgili olarak işletmelere ek maliyetler yüklese de uzun vadede kurumsal kültürün oluşması ve yeni teknolojilerin kullanılması sayesinde işletme performansını artırmaktadır. Ayrıca kurumsal sürdürülebilirliğin benimsenmesi, işletmelere toplum nazarında bir meşruiyet kazandırmakta ve toplumsal desteğe sahip olan işletmeler de piyasada rekabet avantajı elde edebilmektedirler. Bunun yanı sıra yatırımcilar açısından da işletmelerin sürdürülebilirliği önemli bir faktör olmaktadır. Finansal, çevresel, sosyal ve kurumsal yönetimle ilgili riskleri başarılı şekilde yöneten işletmeler gerek yerli gerekse yabancı yatırımcıların ilgisini çekmekte ve ihtiyaç duydukları fonları para ve sermaye piyasalarından kolaylıkla temin edebilmektedirler (Gücenme Gençoğlu ve Aytaç, 2016, s. 64).

Bu bilgiler 1şığında, faaliyetlerinin sürekliliği için büyük önem arz eden doğal kaynakları etkin şekilde kullanıp hammadde güvenliğini temin eden, maliyetlerini düşüren, paydaşlarıyla şeffaf iletişim içerisinde olan, yatırımcıların ve tüketicilerin güvenini kazanan işletmeler uzun vadede sürdürülebilirliklerini garanti altına alabilmektedirler (Aras ve Sarığlu, 2015, s. 25). Ülke ekonomilerinin en önemli aktörleri olmaları bakımından, işletmelerin sürdürülebilir yapıda faaliyet göstermeleri de doğrudan kalkınma çabalarına etki etmekte ve sürdürülebilir kalkınmaya katkı sağlamaktadır.

\section{Sonuç}

İktisat biliminin ortaya çıkmasında da etkili olan kaynakların kıt olması meselesi, insanlığın sürekli olarak baş etmesi gereken bir sorun olmuştur. Tarihsel olarak ele alındığında, üretim faaliyetlerinin 1700'lü yılların ortalarına kadar genellikle 
emeğe dayalı olarak kısıtlı bir şekilde yapıldığı, buna bağlı olarak doğal kaynakların da kısıtlı bir şekilde kullanıldığı görülmektedir. Ancak 18. yüzyılın ortalarında Avrupa ülkelerinde başlayan sanayileşme hareketleriyle birlikte üretimde makineleşmenin yaygınlaşması neticesinde, insanlar ihtiyaçlarından daha fazla üretim yapmaya başlamış ve üretim artışına bağlı olarak kaynak kullanımı da artmıştır. Söz konusu dönemden 20. yüzyılın başlarına kadar ekonomide hâkim olan Klasik İktisadi Görüş, kalkınmanın ekonomik büyümeye bağlı olduğunu ve ekonomik büyümenin de ancak sanayileşme ile gerçekleşebileceğini savunmuştur. Ancak hem Klasik hem de Keynesyen İktisadi Görüş, ekonomik büyümeye ve sanayileşmeye öncelik verirken doğal çevrenin tahrip edilmesini görmezden gelmiştir. 1960'lı yıllara kadar devam eden bu durumun sürdürülemeyeceği fark edilince, salt ekonomik büyümeye dayalı kalkınma modeli yerini, sosyal ve doğal çevreye önem veren sürdürülebilir kalkınmaya bırakmıştır.

Sürdürülebilir kalkınma olgusu çerçevesinde ülkelerin, refah seviyelerini yükseltirken, gelecek nesilleri de göz önünde bulundurarak hareket etmeleri gerektiği, doğal kaynakların sınırsız olmadığı, kalkınmanın sürekli olabilmesi için doğanın kendini yenileyebilmesine imkân tanınması, üretimde yenilenebilir kaynakların kullanımına öncelik verilmesi gerektiği gibi konular önemsenmeye başlamıştır. Öte yandan sanayi devriminden itibaren doğal kaynakları tüketen, çevresel kirliğe, küresel ısınmaya, biyoçeşitliliğin azalmasına vs. neden olan işletmelerin de artık faaliyetlerinde sorumlu davranmaları ve bunu yayımladıkları raporlarda tüm paydaşlarıyla paylaşmaları yönünde toplumsal talepler de artmaya başlamıştır.

Nitekim kurumsal raporlamanın gelişimine bakıldığında, ekonomik büyümenin öncelendiği 1960'lı yıllara kadar işletmelerin sadece finansal raporlama yaptıkları, 1960'lı y1llardan itibaren değişen koşullardan ötürü ve toplumun işletmelerden olan beklentileri neticesinde, süreç içerisinde finansal raporlamanın yanında, kurumsal sorumluluk raporları, kurumsal sosyal sorumluluk raporları, kurumsal yönetim ilkelerine uyum raporları, faaliyet raporları ve son olarak bu raporların yerine sürdürülebilirlik raporları yayımlanmıştır. Finansal raporların yanında yayımlanan söz konusu finansal olmayan bu raporlar, temelde işletmelerin sürdürülebilirlik konusunda paydaşlarını bilgilendirmek için kullandıkları araçlar olmuştur. Ancak farklı zamanlarda ve birbirlerini desteklemeyen hatta bazen birbiriyle çelişen ve aşırı detay bilgiler içeren bu raporlar, başta yatırımcılar olmak üzere bilgi kullanıcılarının ihtiyaç duydukları nitelikli bilgiyi sağlamaktan uzak olmuştur.

Yapılan literatür incelemesi sonucunda da geleneksel kurumsal raporlamanın işletme paydaşlarının gereksinim duyduğu bilgiyi sağlayamadığı anlaşılmıştır. İşletme paydaşlarının ihtiyaç duyduğu nitelikli bilgiyi öz bir şekilde sağlama gereğinden ortaya çıkan entegre raporlama, tek doküman ile finansal ve 
sürdürülebilirlik bilgilerinin paylaşılmasını sağlamaktadır. Kurumsal yönetim ilkeleriyle uyumlu şekilde hazırlanan entegre raporlar işletmelerin şeffaflığına ve hesap verebilirliğine katkıda bulunmaktadır. Bunun yanı sıra işletmelerin nasıl sürdürülebilir değer yarattıkları da entegre raporlama ile açıklanabilmektedir.

İlgili literatüre bakıldığında, işletmelerin artık sadece kârlılıklarının değil bu kârlılığı nasıl sağladıklarının ve durumun sürdürülebilir olup olmadığının da önemli kıstaslar hâline geldiği anlaşılmaktadır. Bu bakımdan kurumsal itibarını artırmak ve toplumun güvenini kazanmak isteyen işletmelerin, faaliyetleriyle ilgili gerek finansal gerekse sosyal ve çevresel etkilerini paydaşlarıyla şeffaf bir şekilde paylaşması gerekmektedir. Öte yandan para ve sermaye piyasalarının sağlıklı gelişimi için de zaruri olan nitelikli bilgiyi yine entegre raporlama ile sağlamak mümkündür.

Sonuç olarak sürdürülebilir kalkınma hedeflerine ulaşmak isteyen ülkelerin sürdürülebilir yapıda faaliyet gösteren işletmelere sahip olması gerekmekte ve işletmelerin sürdürülebilir şekilde faaliyette bulunabilmeleri için de güvenilir, şeffaf, hesap verebilen, katma değer yaratan, insana ve çevreye saygilı işletmeler olduklarını topluma göstermeleri gerekmektedir. $\mathrm{Bu}$ bakımdan, işletmelerin kendilerini en iyi ifade edebilecekleri kurumsal raporlama biçiminin de entegre raporlama olduğu söylenebilir. 


\section{Kaynakça}

Akgül, U. (2010). Sürdürülebilir kalkınma: uygulamalı antropolojinin eylem plan1. Antropoloji, (24), 133-164.

Aksoy, F. (2019). İşletmelerde sürdürülebilirlik raporlama çerçeveleri. Muhasebe Bilim Dünyası Dergisi, 21(2), 324-346.

Altunbaş, D. (2003). Uluslararası sürdürülebilir kalkınma ekseninde Türkiye'deki kurumsal değişimlere bir bakış. Yönetim Bilimleri Dergisi, 1(1-2), 103118.

Aras, G. ve Sarığlu, G. U. (2015). Kurumsal raporlamada yeni dönem: entegre raporlama. İstanbul: TÜSİAD Yayınları, Yayın No: T/2015,10-567.

Ataçay, M. N. (2020). Çin reform tecrübesinin kalkınma kavramı çerçevesinde yeniden değerlendirilmesi. Uluslararası Yönetim İktisat ve Isşletme Dergisi, $16(2), 442-456$.

Aydın, S. (2015). Entegre raporlama. İstanbul Türkmen: Kitabevi.

Banik, A. (2015). Conclusions. A. Banik, A. D. Gupta and P. K. Bhaumik (Ed.). Corporate governance, responsibility and sustainability: initiatives in emerging economies içinde (s.158-163). London: Palgrave Macmillian.

Battal, Ü. (2018). Sürdürülebilirlik raporlaması ve entegre raporlama: Türk Hava Yolları ve Güney Afrika Hava Yolları incelemesi. Muhasebe ve Vergi Uygulamaları Dergisi, 11(3), 393-423.

Bhasin, L. M. (2017). Integrated Reporting: the future of corporate reporting. International Journal of Management and Social Sciences Research, 6(2), $17-31$.

Bozlağan, R. (2010). Sürdürülebilir gelişme düşüncesinin tarihsel arka planı. Journal of Social Policy Conferences, 0(50), 1011-1028.

Cliffe Dekker Attorneys (t.y.). King report on corporate governance for South Africa 2002. https://www.mervynking.co.za/downloads/CD_King2.pdf. (Erişim Tarihi: 18.09.2021).

Çalkıvik, K. (2013). Entegre raporlama dönemi başlıyor. EKOIQ, (32), 74.

Doğru, B. (Ed.) (2017). 100 maddede sürdürülebilirlik rehberi. İstanbul: SKD Türkiye. 
Dräger, H. (2014). Daha anlamlı kurumsal raporlamaya yeni yaklaşımlar. Kurumsal Yönetim Dergisi, (24), 42-43.

Ergün, T. ve Çobanoğlu, N. (2012). Sürdürülebilir kalkınma ve çevre etiği. Ankara Üniversitesi Sosyal Bilimler Enstitüsü Dergisi, 3(1), 97-123.

Giddings, B., Hopwood, B. ve O'Brien, G. (2002). Environment, economy and society: fitting them together into sustainable development. Sustainable Development, 10(4), 187-196.

GRI (16.09.2021). https://www.globalreporting.org/.

GRI (2014). G4 sürdürülebilirlik raporlaması kılavuzları: raporlama ilkeleri ve standart bildirimler. https://surdurulebilirlik.garantibbva.com.tr/media/1059/turkish-g4-partone.pdf. (Erişim Tarihi: 19.08.2021).

Gücenme Gençoğlu, Ü. ve Aytaç, A. (2016). Kurumsal sürdürülebilirlik açısından entegre raporlamanın önemi ve BIST uygulamaları. Muhasebe ve Finansman Dergisi, (72), 51-66.

IIRC (2011). Towards integrated reporting communicating value in the $21 \mathrm{st}$ century. https://integratedreporting.org/wp-content/uploads/2011/09/IRDiscussion-Paper-2011_spreads.pdf. (Erişim Tarihi: 29.08.2021).

IIRC (2013). Uluslararas1 <ER $>$ çerçevesi. https://integratedreporting.org/wpcontent/uploads/2015/03/13-12-08-THE-INTERNATIONAL-IRFRAMEWORK-Turkish.pdf. (Erişim Tarihi: 29.08.2021).

Institute of Directors Southern Africa (2009). King report on governance for South Africa 2009. https://cdn.ymaws.com/www.iodsa.co.za/resource/resmgr/king_iii/King_R eport_on_Governance_fo.pdf. (Erişim Tarihi: 29.08.2021).

Kanzer, A. M. (2010). Toward a model for sustainable capital allocation. R. G. Eccles, B. Cheng and D. Saltzman (Ed.). The landscape of integrated reporting reflections and next steps içinde (s. 45-57). Massachusetts: Harvard Business School.

Karabıçak, M. ve Armağan, R. (2004). Çevre sorunlarının ortaya çıkış süreci, çevre yönetiminin temelleri ve ekonomik etkileri. Süleyman Demirel Üniversitesi İktisadi ve İdari Bilimler Fakültesi Dergisi, 9(2), 203-228.

Karabıçak, M. ve Özdemir, M. B. (2015). Sürdürülebilir kalkınmanın kavramsal temelleri. Süleyman Demirel Üniversitesi Vizyoner Dergisi, 6(13), 44-49. 
Kaya, H. P. (2015). Entegre raporlama sisteminin ortaya çıkış sebepleri ve şirketlere sağlayacağı faydalar. Muhasebe ve Denetime Baklş, (45), 113130.

Kevser, M. (2020). Entegre raporlama ve kamu bankalarında uygulanabilirliği üzerine karşılaştırmalı bir araştırma. İşletme Araştırmaları Dergisi, 12(4), 4231-4251.

King, M. ve Roberts, L. (2017). Entegre düşünce. (E. Erimez, Çev.). İstanbul: Argüden Yönetişim Akademisi Yayınları, Yayın No: 10.

Krzus, M. P. (2011). Integrated reporting: if not now, when?. IRZ, Heft 6, Juni, 271-276.

Mıhçı, H. (1996). Kalkınma: bir terim neyi anlatır?. Ekonomik Yaklaşım, 7(23), 65-86.

Morros, J. (2016). The integrated reporting: a presentation of the current state of art and aspectsof integrated reporting that need further development. Intangible Capital, 12(1), 336-356.

Önder, Ş. (2017). İşletme karlılığına kurumsal sürdürülebilirliğin etkisi: BİST'te bir uygulama. Muhasebe Bilim Dünyası Dergisi, 19(4), 937-956.

Önder, Ş. (2018). Kurumsal raporlamanın yeni trendi entegre raporlama. Bursa: Ekin Basım Yayın Dağıtım.

Öztürk, S. (2019). Geleceğin kurumsal raporlama yaklaşımı olarak entegre raporlama: Garanti Bankası örneği. Muhasebe ve Finansman Dergisi, (81), $1-20$.

Sevim, Ș. ve Bayhan, B. (2018). Kamu sektöründe entegre raporlama: üniversitelerde entegre raporlama mimarisi. Ankara Gazi: Kitabevi.

Soubbotina, T. P. (2004). Beyond economic growth: an introduction to sustainable development. Second Edition. Washington: The World Bank.

Tıraş, H. H. (2012). Sürdürülebilir kalkınma ve çevre: teorik bir inceleme. Kahramanmaraş Sütçü İmam Üniversitesi İktisadi ve İdari Bilimler Fakültesi Dergisi, 2(2), 57-73.

TKYD (2014). Dünyadan haberler. Kurumsal Yönetim Dergisi, (24), 18.

Toprak, D. (2006). Sürdürülebilir kalkınma çerçevesinde çevre politikaları ve mali araçlar. Süleyman Demirel Üniversitesi Sosyal Bilimler Enstitüsü Dergisi, 2(4), 146-169. 
UN (1987). Report of the world commission on environment and development: our common future. https://www.are.admin.ch/are/en/home/media/publications/sustainabledevelopment/brundtland-report.html. (Erişim Tarihi: 11.12.2021).

WBCSD (2014). Integrated reporting in South Africa: from concept to practice. https://integratedreporting.org/resource/integrated-reporting-in-southafrica-from-concept-to-practice/. (Erişim Tarihi: 18.09.2021).

Yavilioğlu, C. (2002). Kalkınmanın anlambilimsel tarihi ve kavramsal kökenleri. C.Ü. Íktisadi ve İari Bilimler Dergisi, 3(1), 59-77.

Yaylı, H. (2012). Çevre etiği bağlamında kalkınma, çevre ve nüfus. Süleyman Demirel Üniversitesi Sosyal Bilimler Enstitüsü Dergisi, (15), 151-169.

Yıldırım, G. ve Uzun Kocamış, T. (2018). Entegre raporlama: sürdürülebilir ve daha iyi bir yönetim için entegre raporlama. İstanbul: Türkmen Kitabevi. 


\title{
Conceptual Framework for The Impact of Integrated Reporting on Sustainable Development and Businesses
}

\author{
Extended Abstract
}

\section{Introduction}

Throughout history, human beings have benefitted from the surrounding resources to survive. Until the industrial revolution in the 18th century, the ecological equilibrium was not damaged because the resources used by humankind did not exceed the capacity of nature to rejuvenate itself. However, the mechanization, mass production, and excessive consumption starting with the industrial revolution brought along the excessive consumption of natural resources; moreover, the fact that the governments took the development identical to industrialization and economic growth caused the ecological balance to be quickly disrupted. The natural environment, sacrificed for the sake of countries' economic growth until the 1960s, drew attention from that time on as it failed to rejuvenate itself; thus, the concept of development left its place over to sustainable development since the 1970s. Since those years, various international institutions and organizations, governments, and various non-governmental organizations, primarily the United Nations, have worked on issues envisaging businesses both to carry out more environment-sensitive activities and share them with society through their reports. Indeed, when looking into the history of corporate reporting, it is observed that enterprises carried out purely profit-oriented activities, made only financial reporting until the 1960s, and since then, published various non-financial reports as well as financial ones, as a result of changing economic conditions and society's expectations. However, that the numerous reports published by the businesses were both lengthy and over-detailed, and even failing to establish a connection between the financial data and the sustainability data caused an insufficiency for meeting the qualified information needs of business stakeholders, primarily the investors. In order to meet the qualified information needs of business stakeholders concisely, the concept of integrated reporting has been included in corporate reporting. The aim of this study is to scrutinize the consequence of integrated reporting practice, which is a new approach in corporate reporting, on businesses and sustainable development.

\section{Theoretical Framework}

Adverse conditions such as global warming, climate change, extinction of living species, largescale forest fires, pollution of the air and seas, and finally, the COVID-19 pandemic being suffered worldwide since 2019 have strikingly revealed the importance of protecting the natural environment and the resources. The adversary conditions occurring in the natural environment and the public awareness on ecology stipulated the countries and the businesses, previously ascribing their sustainability to economic growth and financial profitability, to put the protection of the environment and the environmental policies on their agenda. Today, investors and other stakeholders care not only about the financial profitability of businesses but also about how this profitability is achieved and whether it is sustainable in the long term. Therefore, in order for businesses to meet these expectations, it does not suffice to publish financial reports alone, so they publish sustainability reports as well. However, the independent publication of those two report types fails to fully reflect the mutual interaction of the data in each of the reports. In fact, after the global financial crisis in 2008, when the deficiencies of traditional reporting were clearly figured out, the integrated reporting practice started to occupy much more space on the agenda of businesses all around the world. 


\section{Conclusion}

Today, when trust is quite substantial in the business world, transparency and accountability are essential for the dignity of businesses in the public's esteem. Corporate reporting needs to be as effective as possible, as it is the most important instrument of businesses for expressing themselves and communicating with their stakeholders. Considering the change that corporate reporting has undergone from past to present, it is observed that integrated reporting practice can be the most effective instrument of transparency and accountability for businesses. This is because through that form of reporting, businesses can concisely reveal how they create value in the short, medium, and long term, and the financial results of their non-financial activities, and share their business models and future-oriented strategies with their stakeholders. Thus, the businesses, which meet the information requirements of their stakeholders and stay in transparent communication with them, can be considered being exempt from the dignity risk.

To conclude, countries need businesses operating in sustainable structures for the achievement of their sustainable development goals. Businesses have to make profit in order to gain a sustainable structure, and today, a business has to respond to social demands to make profit. When viewed from this aspect, integrated reporting practice can be considered to positively affect the sustainability of the businesses, and therefore sustainable development.

As an advice to researchers who will work on integrated reporting in the future, they can meet with the managers of integrated reporting companies and get information about the positive and negative effects of this type of reporting. 